\title{
Ophthalmic pathology in the electronic age
}

Ophthalmic pathology has traditionally played an important role in diagnosis in clinical ophthalmology, research into ophthalmic disease, and postgraduate education. Until recently the technical methods that are the mainstay of diagnostic pathology, such as paraffin histology, electron microscopy and immunohistochemistry, were the same techniques that were used in laboratory-based ophthalmic tissue research. Increasingly, however, the modern methodologies of molecular biology and the biological sciences are making a major impact on the practice of both diagnostic ophthalmic pathology and research into the causes and treatment of ophthalmic diseases. There has been a massive expansion of published highly specialised information that may be applicable to both diagnosis and research in ophthalmic pathology. As a result of this, the ophthalmic pathologist must communicate with professionals with skills in a wide range of modern molecular and biological scientific disciplines if the subject (and ultimately the patient) is to benefit from scientific advances. This is vitally important if we are to maximise the information available from the examination of (often small) tissue samples removed from patients with ophthalmic diseases that may be rare, or where specific treatment regimes are required.

The development and implementation of changes in the practice of ophthalmic pathology is, however, hindered by the fact that in most countries in the world there are relatively small numbers of professionals involved in the discipline, and these come from widely differing backgrounds (such as histopathology, biochemistry, microbiology and genetics). Geographical dispersion impedes the ability of colleagues to exchange ideas and learn of the developments in clinical ophthalmology, the practices and research activities of other groups, and advances in other relevant disciplines in pathology or the biological and molecular sciences. The published literature is only partially helpful in these respects, as papers pertinent to ophthalmic science are published internationally in an increasingly wide range of journals, with no specific journal dedicated to ophthalmic pathology, and very limited budgets for the purchase of expensive journals, even at institutional level. National and international meetings go some way to providing focal points for discussion, but these are relatively restricted in their content (e.g. research-based or diagnosis-based) and they may be relatively poorly attended for both geographical and financial reasons. Neither papers in journals nor international meetings provide an opportunity for interactive discussion in the short term.

Ophthalmic pathology is one of the smallest sub-specialities in histopathology, and many ophthalmic pathologists feel the need to counter their relative isolation by improving their communication and collaboration with colleagues if they are to make a significant contribution to the practice of ophthalmology and to the advancement of ophthalmic sciences. Such communication within the discipline is also essential 'politically' to address issues such as the funding of posts, training, recruitment, and the development and maintenance of high professional standards. There are also many benefits to be gained through improved communication leading to the pooling of expertise and resources, the establishment of national and international consensus in diagnostic standards, and collaboration in research and teaching initiatives.

How might these benefits be achieved? The current 'electronic revolution' is starting to provide some solutions - at least for those with a personal computer and Internet access. The technology of the Internet ${ }^{1}$ has, for some time, provided the ability to search remote databases (e.g. the bibliographical databases such as Medline and EMBASE) and has already proved invaluable to the geographically isolated professional. In addition, several world wide web sites (WWW; perhaps the most familiar component of the Internet) that are of special interest to the ophthalmic pathologist and scientist have become available more recently (Table 1). Some of these remain of limited use, however, as they provide frontispiece advertisements for specific laboratories, or give initial information about Societies with limited membership that requires contact with
B.J. Clark

Department of Pathology Institute of Ophthalmology Bath Street London EC1V 9EL, UK

Tel: $+44(0) 1716086808$ Fax: +44 (0)1716086862 e-mail: brian.clark@ucl.ac.uk

\section{M.A. Parsons}

Ophthalmic Sciences Unit Royal Hallamshire Hospital Sheffield S10 2JF, UK 
Table 1. Some web sites related to ophthalmic pathology

\begin{tabular}{ll}
\hline URL (web address) & Description \\
\hline http://pathology.mc.duke.edu/EyePath/EyePath.htm & $\begin{array}{l}\text { An informative site of introduction to ophthalmic pathology, its } \\
\text { scope, its societies and activities. Provides links to many of the } \\
\text { other sites listed below }\end{array}$ \\
http://www.helsinki.fi/laak/silk/perus/eopshome.hmtl & $\begin{array}{l}\text { The home page of the European Ophthalmic Pathology Society } \\
\text { (EOPS). This society, in existence since 1962, is an exclusive group } \\
\text { of invited membership. The site details its history, the membership, } \\
\text { its meetings, and a wealth of information on all the diagnostic cases } \\
\text { presented }\end{array}$
\end{tabular}

http://pathology.mc.duke.edu/EyePath/vs.htm

http://pathology.mc.duke.edu/EyePath/eops.htm

http://webeye.ophth.uiowa.edu/dept/pathlab/homepage.htm

http://www.eyenet.org/alt_aao_index.html

http://www.faseb.org/arvo/

http://www.helsinki.fi/laak/silk/oog/ooghome.html
The home page of the Verhoeff Society. This is a North American group, existing since 1947 and with limited membership, akin to EOPS with which it holds joint meetings every 5 years. This site is a resource of diagnostic case studies, and information on membership and meetings

The home page of the Eastern Ophthalmic Pathology Society in North America. This is a smaller group, in operation since 1962, concerned primarily with diagnostic ophthalmic pathology

A good example of an institutional home page. This is the gateway to the activities and services of the FC Blodi Eye Pathology Laboratory of the University of Iowa, USA. This provides information on diagnostic and research work, as well as opportunities for electronic 'distance learning' study in ophthalmic pathology

The home page of the American Academy of Ophthalmology (AAO). This provides a gateway to the members, meetings and services of the AAO, as well as the meetings of the American Association of Ophthalmic Pathology (AAOP). The latter is a forum for the discussion of both diagnostic problems and research. It holds biannual meetings with the International Society of Ophthalmic Pathology

The web site of the Association for Research in Vision and Ophthalmology (ARVO). This is the forum for much of the world's research in ophthalmic pathology. This site provides access to the meetings, membership, policies, and other activities of ARVO

The home page of the Ophthalmic Oncology Group, an international body devoted to the study of ophthalmic tumours. This group is multidisciplinary and includes pathologists individual members. Often, however, it is much more desirable to have direct communication and discussion with other professionals, and this is now feasible and relatively easily achieved by the use of electronic mail (email; the most ubiquitous component of the Internet). Discussion groups based on e-mail offer simultaneous contact with many professionals in the discipline, through a single e-mail address, and provide the opportunity to contact individuals without prior knowledge of their interests, skills or even their individual e-mail address. E-mail discussion groups enable participants to:

Consult on and discuss diagnostic cases with colleagues with special expertise

Discuss the availability of tissues, cells, DNA, etc. for research

Discuss techniques applicable to the study of ocular tissues

Distribute material such as papers, minutes, reports and data

Advertise posts and fellowships

Publicise conferences and seminars.
Files submitted to the discussion group need not be based on text alone, as histological or other photographs can be transmitted as digitised electronic graphics files. Such files can be produced by: (1) electronic scanning of photographs, radiographs or photographic transparencies; or (2) directly digitising video camera images (without the need to first generate any photographic hard copy) via relatively inexpensive digital conversion hardware attached to a personal computer (e.g. Snappy Video Snapshot, Play Incorporated, Rancho Cordova, California, USA).

Highly successful e-mail discussion groups exist in many areas of medicine and science and there is great potential for such a group in ophthalmic science. In 1997, an e-mail discussion group specifically aimed at ophthalmic pathologists and scientists was launched on the Internet, and is listed as 'eyepathology'. Membership of this group is open to those (medical practitioners or scientists) who can demonstrate a genuine professional interest in the study of eyes and ocular disease at the tissue, cell or molecular level, whatever their discipline or scientific methodology. The research interests of the 
group are currently broad-based, with some emphasis on tumours, development, genetic eye disease and ocular immunology, but the future topics for discussion will be determined by the membership. Membership of eyepathology can be obtained by sending an e-mail message introducing yourself and your interest in joining to the list 'owner' (currently Dr Brian J. Clark) at the eyepathology-request@mailbase.ac.uk address. The only requirements are a computer with Internet access and an e-mail address, which may be institutional or private. There is no additional charge for participation in the group. The eyepathology world wide web site at http:// www.mailbase.ac.uk/lists/eyepathology/ provides further information.

What does the future hold for electronic communication in ophthalmic pathology and the ophthalmic sciences? It is likely that e-mail will remain the most widely used form of electronic communication over the next five years or more, since it is the 'lowest common denominator' on the Internet. Even in five years time colleagues in developing countries may not have access to new technologies such as video-conferencing, expensive 'groupware' or even the WWW, but almost certainly they will have an e-mail address. Since e-mail does not interrupt work, unlike a 'phone call which must be answered or a video-conference which must be 'attended', it can be consulted at a convenient time (although world time zones impart an interesting dimension to short-term international discussions). It is feasible to access e-mail on a portable computer that can be read at home, in a hotel or even on the train. One potential use of e-mail is as a method for holding electronic conferences of peers with discussion available to all participants. Unlike a conventional conference, which requires funding and the attendance of many hundreds to be worthwhile, valuable information can be obtained through an e-mail discussion list of appropriate collaborators. This is especially so in conjunction with associated documents or pictures made available on the WWW. Pictorial archives for teaching and diagnostic reference, with links to associated text discussion, may become established to allow remote access to details of rare or precious material, with potentially enormous financial and time savings.

So, will an increase in our use of electronic communication solve all our problems in ophthalmic pathology, heralding an age of peace and enlightenment, and showering blessings on our patients and medical/ academic institutions? A cynical (or perhaps realistic) extrapolation of Newtonian physics (Murphy's-Newton Law, perhaps?) could well state 'for every useful advance there is an equal but opposite disadvantage', and for this reason a few words of warning to potential users of email systems/discussion groups are appropriate at this stage:

Information sent by e-mail to another party either nationally/internationally (or even within an institution) must be regarded as 'in the public domain', and therefore subject to the same constraints as publication in journals, newspapers or on television. This has several important implications:

1. Discussions on diagnostic pathology, medicolegal cases, case reports, etc., must be constrained by the absolute requirement to maintain patient confidentiality. Remember that patients may be identified not only by name, but also by their age, date of birth, ethnicity, patient or laboratory record number, full (or partial) address, personal or 'disease' details, and any combination of these. An e-mail discussion group's current and archival material may not be so secure as to prevent entry by those who would delight in obtaining information on a current medicolegal case (exposure of diagnostic errors, criticism of colleagues, 'the medical case for the prosecution', etc.).

2. Libel laws apply to material transmitted by electronic means, in the same way as though transmitted by paper.

3. Issues of intellectual property rights are worthy of consideration before launching your 'big idea' into the electronic ether. Ownership of intellectual property is sometimes hard to prove, and we advise that readers consult the appropriate authority within their institution if they are unsure about the details of this issue.

4. Electronic 'diagnostic ophthalmic pathology' consultations also raise potentially problematical issues. Consider the scenario when general pathologist $A$ sends an e-mail to ophthalmic pathologist $B$, attaching good-quality digitised images of one or two microscope fields selected from an ophthalmic specimen. Pathologist B, the 'expert', sends a reply containing a diagnosis, which is then passed to the ophthalmic surgeon, and upon which the surgeon bases the subsequent management of the patient. This may be very useful, but it is also a potential recipe for disaster: pathologist A selects the wrong area of the specimen (sampling error); pathologist $B$ makes an incorrect diagnosis on the picture (diagnostic error), or fails to consider the possibility of sampling error (interpretational error, or failure of adequate communication); pathologist $\mathrm{A}$ fails to consider that the 'expert's' diagnosis may be subject to sampling error (interpretational and/or communication error); the surgeon is unaware that the diagnosis received is the result of the above procedure. Who is responsible for the error? Which institution is sued? Does the professional liability insurance of ophthalmic pathologist B cover this type of consultation? These issues are important (and we do not exclude the possibility that there may be more which we have not considered), but they should not inhibit the intelligent use of electronic communication networks in ophthalmic pathology.

As the 'electronic revolution' proceeds, there is no doubt that ophthalmic pathologists and scientists will reap its benefits, and, it is hoped, will pass these in turn 
to 'the consumer' - the patient with eye disease. As pathologists, we are familiar with the concept of the need to incorporate new molecular and biological scientific methodologies into the practice of our discipline.

However, we often forget that our capacity for thought and reason is our most important diagnostic and scientific resource. Modern electronic communication systems will allow us to link our individual powers of reason with those of others, and this 'harnessing of collective experience, reason and wisdom' is a technological advance that we must embrace with enthusiasm.

\section{Reference}

1. Kennedy AJ. The Internet \& World Wide Web. The rough guide 1998. London: Rough Guides, 1998. 